\title{
Synthesis of Nitrogen-Containing Chalcone Via One-Pot Three-Component Reaction • part ii
}

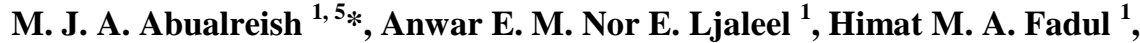 \\ Saad M. H. Ayuob ${ }^{2}$, M, Abdel Karim ${ }^{3}$, Jan H. Van Der Westhuizen ${ }^{4}$ \\ ${ }^{1}$ Department of Chemistry, Faculty of Science, Omdurman Islamic University, Khartoum- Sudan \\ ${ }^{2}$ Department of Pharmaceutical Chemistry, Faculty of Pharmacy, El-Neeilain University, Khartoum \\ ${ }^{3}$ Departments of Chemistry, Sudan University of Science and Technology, Faculty of Science, Khartoum-Sudan \\ ${ }^{4}$ Department of Chemistry, Faculty of Agriculture and Science, University of Free state, Bloemfontein-South Africa \\ ${ }^{5}$ Department of Chemistry, Faculty of Science, Northern Border University, Arar, Kingdom of Saudi Arabia \\ *Corresponding author E-mail: Mustjeed_2008@hotmail.com
}

\begin{abstract}
The compound 3-Hydroxy-4'-methoxychalcone (1) was prepared by reacting 3-hydroxybenzaldehyde with 4-methoxyacetophenone. The aminomethylation of this chalcone was accomplished by reaction with formaldehyde and $\mathrm{N}$-methylpiperazine in dry acetonitrile to Obtain 3-hydroxy-4'-methoxy-4-(N-methyl-piperazinomethyl) chalcone (2) and 3-hydroxy-4'-methoxy-2,4-bis-(Nmethylpiperazinomethyl)chalcone(3). The products were purified by column and thin layer chromatography and were identified along with their intermediates by spectroscopic methods: UV, IR, NMR and mass spectrometry.
\end{abstract}

Keywords: Chalcone; 3-Hydroxybenzaldehyde; 4-Methoxyacetophenone; Aminomethylation; Formaldehyde ; N-Methylpiperazine.

\section{Introduction}

Mannich reaction is a condensation reaction between (i) ammonia , primary or secondary amines (ii) an active hydrogen compound and (iii) formalin. The product of such condensation is known as a Mannich base.

Studies on the chemistry of Mannich bases are of interest in various areas of applications. A large number of aminoalkyl derivatives have been synthesized in order to correlate their structure and reactivity with their pharmacological potential. Also Mannich bases represent easily obtainable intermediates for the synthesis of other compounds such as heterocycles, aminoalcohols ...etc.

Chalcones, which are considered to be precursors of flavonoids, are abundant in edible plants. Chemically, they are open chain flavonoids in which the two aromatic rings are joined by a threecarbon $\alpha, \beta$-unsaturated carbonyl function.

Mannich bases are known for their biological potential. Some Mannich bases posses anticonvulsant ( Mutlu \& Vnsal 2007), (Ozan et. al 2005), analgesic (Nabil et.al 1993), cytotoxic (Robert et.al 2006), (Ina-Gull et.al 2000), (Ebru et.al 2007), (Jontathan et.al 2002). Antimalarial (Stephen et.al 1987), antibacterial (Tamas et.al 2002), antimicrobial (Afaf et.al 2000) and anticancer activity (Janathan et.al 1998), (Dimmock \& Kamar 1997). Chalcones exhibit diverse pharmacological activities, including anti- inflammatory (Abraham et. al 2003), ( Herencia et. al 1998 ), antimitotic (Ko et.al 2003 ), antitubercolosis( Lin et. al 2002 ), antifungal( Lopez et. al 2001 ), antimalarial. (Li et. al 1995), (Parmer et. al 2003) properties.

Bearing such interesting properties of Mannich bases and chalcones in mind, it was decided to join Mannich bases and chalcones in one molecule, probably which potential pharmacological activities. The target molecule is approached via effective and facile strategy involving synthesis of chalcones and subsequent aminomethylation.

\section{Experimental}

\subsection{Instruments}

IR spectroscopy was carried out using Spectrum BX instrument model L1050033, UV/VIS spectroscopy was carried out using Beckman Coulter instrument model DU 800 Spectrophotmeter. NMR spectroscopy was carried out using Procker instrument model AvanceII 600 and using Procker instrumen AvanceII 300 and MS spectroscopy was carried out using MDS SCIEX instrument modelAPI 2000 LC/ MS/MS System.

\subsection{Synthesis of 3-hydroxy-4'-methoxychalcone (1)}

$10 \mathrm{ml}$ of $10 \%$ sodium hydroxide solution were added to a solution of the 4-methoxyacetophenone $(0.02 \mathrm{~mol})$ and 3-hydroxybenzald-ehyde $(0.02 \mathrm{~mol})$ in ethanol $(6 \mathrm{ml})$.The mixture was stirred at room temperature for $24 \mathrm{~h}$ and poured into water $(100 \mathrm{ml})$. After neutralization with $10 \%$ hydrochloric acid a yellow solid was obtained. m.p 150-153 ${ }^{\circ} \mathrm{C}$ (yield 80\%).

\subsection{Synthesis of Chalcone substituted with Mannich side chain}

A mixture of 3-hydroxy-4'-methoxychalcone(1) (0.005 mol), formalin $(0.01 \mathrm{~mol})$ and $\mathrm{N}$-methylpiperazine $(0.01 \mathrm{~mol})$ were 
reacted in dry acetonitrile $(50 \mathrm{ml})$ and heated under reflux for $36 \mathrm{~h}$. On cooling a precipitate was formed and the crude products were fractionated on silica gel $G$ using the solvent system: hexane/ethylacetatel/methanol 6:3:1 .Two products were obtained 3-hydroxy-4'-methoxy-4-(N-methylpiperazinomethyl) chalcone(2) as pale yellow crystals, m.p136-137 ${ }^{\circ} \mathrm{C}$, (yield 60\%) and 3-hydroxy-4'-methoxy-2, 4-bis-(N-methylpiperazinomethyl) chalcone (3) also as pale yellow crystals, m.p $122-123{ }^{\circ} \mathrm{C}$, (yield $58 \%)$.

\section{Results and discussion}

3-hydroxy-4'-methoxychalcone (1) was prepared according to the procedure outlined above, and also two other chalcones with Mannich side chain (2) and (3) were prepared together with their intermediate according to the following scheme :

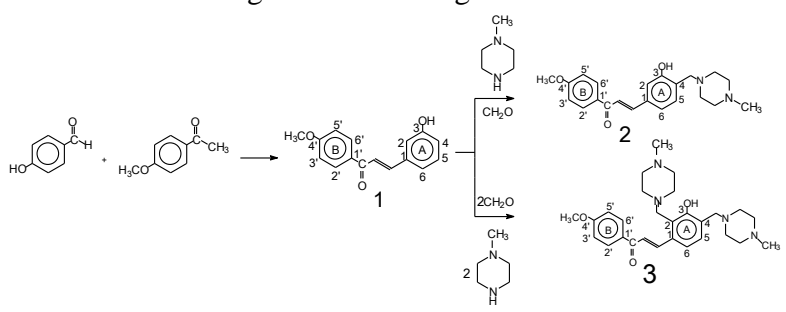

The UV spectrum of compound (1) (Fig (1) a ) showed $\lambda_{\max }$ (etha-nol), 260, 310 and $386 \mathrm{~nm}$ due to the benzoyl and cinnamoylchromophores. The IR spectrum $v(\mathrm{KBr})$ (Fig (1) b ) showed 831 (C-H, Ar, bending), $1168.7(\mathrm{C}-\mathrm{N}) 1263(\mathrm{C}-\mathrm{O}), 1510$, 1556 and 1591 ( $\mathrm{C}=\mathrm{C}$, Ar, st,vib), 1650.9 (C=O. st, vib), 2840 (C$\mathrm{H}$ aliphatic), 2966 (C-H Ar) and $3340(\mathrm{OH}) \mathrm{cm}^{-1}$. The ${ }^{1} \mathrm{H}-\mathrm{NMR}$ spectrum of compound (1) (Fig (1) c ) showed $\delta 7.51(\mathrm{~d}, 1 \mathrm{H}, \mathrm{J}=$ $16.6 \mathrm{~Hz})$ and $\delta 7.73(\mathrm{~d}, 1 \mathrm{H}, \mathrm{J}=16.6 \mathrm{~Hz})$ corresponding to $\alpha$ and $\beta$ protons respectively. The signal at $\delta 7.09$ (d, J 7.0 Hz, 2H), was assigned for $\mathrm{C}_{2}, 6^{-}, \mathrm{H}$, while the signal at $\delta 8.15(\mathrm{~d}, \mathrm{~J} 7.0 \mathrm{~Hz}, 2 \mathrm{H})$,

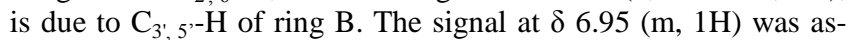
signed for $\mathrm{C}_{6}-\mathrm{H}$, while the resonance at $\delta 7.27(\mathrm{~m}, 3 \mathrm{H})$ is characteristic of $\mathrm{C}_{2}, \mathrm{C}_{3}$ and $\mathrm{C}_{4}$ protons. The mass spectrum of compound (1) (Fig (1) e ) gave $\mathrm{m} / \mathrm{z} 255.10132$ (100\%) (Base peak) for the molecular ion.

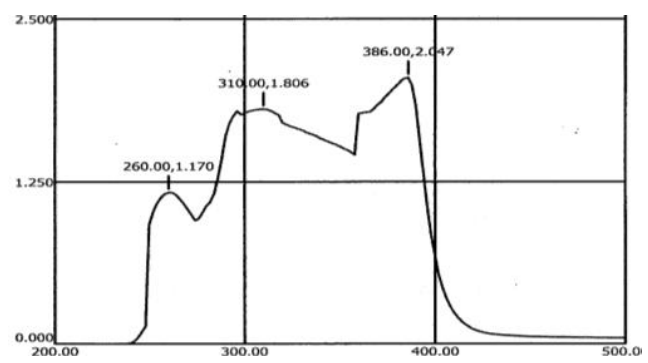

Fig.1, a : UV spectrum of 3-hydroxy-4'-methoxychalcone (1).

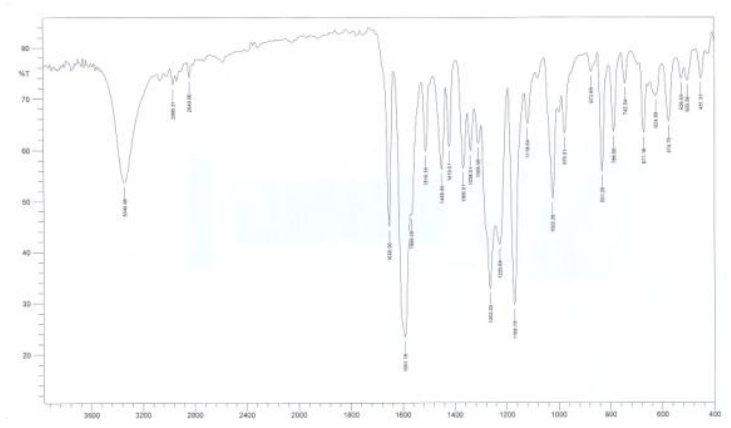

Fig.1, b : IR spectrum of 3-hydroxy-4'-methoxychalcone (1).

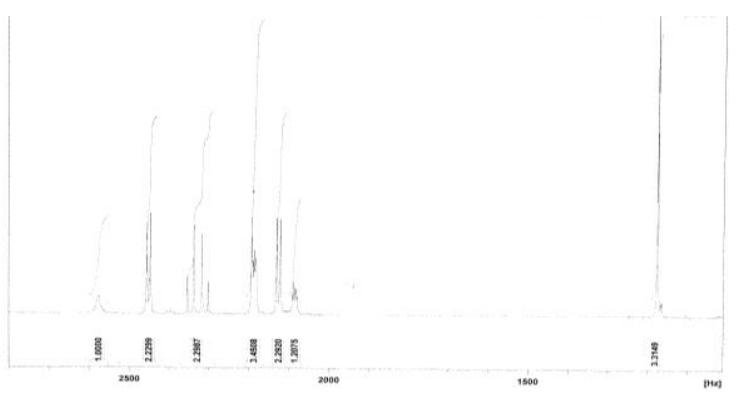

Fig.1, c : ${ }^{1}$ HNMR spectrum of 3-hydroxy-4'-methoxychalcone (1).

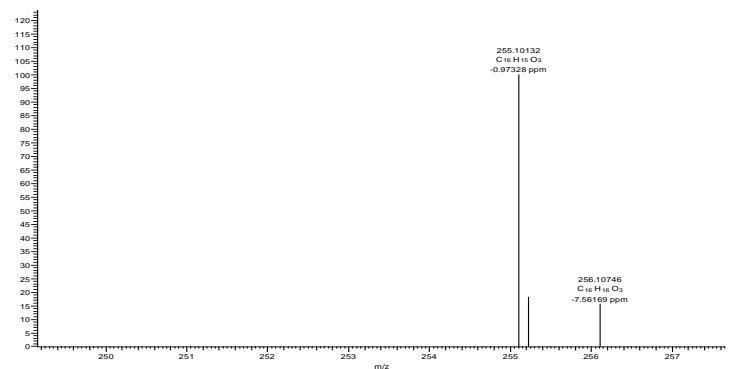

Fig. 1, d :Accurate mass spectrum of of 3-hydroxy-4'-methoxy- chalcone (1).

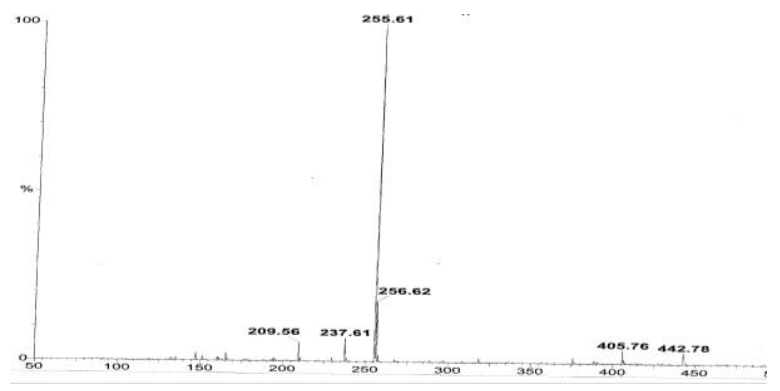

Fig. 1, e :Mass spectrum of 3-hydroxy-4'-methoxychalcone (1).

When 3-hydroxy-4-methoxychalcone, reacted with N-methyl-piperazine and formalin in dry acetonitrile under reflux 3-hydroxy-4'-methoxy-4-(N-methyl-piperazinomethyl) -chalcone(2) was obtained m.p136-137 ${ }^{\circ} \mathrm{C},(60 \%)$. The UV spectrum (Fig (2) a) gave $\lambda_{\max }$ (ethanol) $260,320,335$ and $385 \mathrm{~nm}$. The IR spectrum $v$ (KBr) (Fig (2) b) showed 827 (C-H, Ar, bending), $1164(\mathrm{C}-\mathrm{N}), 1265$ (C-O), 1450, 1510, 1602 (C=C, Ar, st,vib), 1654 (C=O. st, vib), 2765, 2794 (C-H, aliphatic), 2840 (C-H, Ar) and $2931 \mathrm{~cm}^{-1}(\mathrm{OH})$. The ${ }^{1} \mathrm{H}-\mathrm{NMR}$ spectrum (Fig (2) c) showed a singlet at $\delta 2.32(3 \mathrm{H})$ assigned for the methyl group. The multipletcentered at $\delta 2.40$ was assigned for the 8 protons of the $\mathrm{N}$-methylpiperazine ring. The signal at $\delta 3.75(\mathrm{~s}, 2 \mathrm{H})$, is character-

istic of $=\mathrm{N}-\mathrm{CH}_{2}-$ whilst the singlet at $\delta 3.89$ was assigned for the methoxy group.

The resonance at $\delta 6.98(\mathrm{~d}, \mathrm{~J}=8.8 \mathrm{~Hz}, 2 \mathrm{H})$ was assigned for $\mathrm{C}_{3}$ and $\mathrm{C}_{5}-\mathrm{H}$. The resonate at $\delta 8.03(\mathrm{~d}, \mathrm{~J}=8.8 \mathrm{~Hz}, 2 \mathrm{H})$ was assigned for $\mathrm{C}_{2^{\prime}}$ and $\mathrm{C}_{6^{\prime}}-\mathrm{H}$. The doublet at $\delta 7.51(\mathrm{~J}=15.6,1 \mathrm{H})$ was assigned for $\beta-\mathrm{H}$ and the signal $\delta 7.73(\mathrm{~J}=15.6,1 \mathrm{H})$ for the $\alpha-\mathrm{H}$. The doublet at $\delta 7.00\left(1 \mathrm{H}, \mathrm{J}_{6,5} 7.7 \mathrm{~Hz}\right.$, ) was assigned to $\mathrm{C}_{5}-\mathrm{H}$, the signal centered at $\delta 7.13\left(\mathrm{dd}, \mathrm{J}_{6,5} 7.7 \mathrm{~Hz}, \mathrm{~J}_{2,6} \mathrm{~Hz} 1.61 \mathrm{H}\right)$ was assigned for the $\mathrm{C}_{6}-\mathrm{H}$, while the resonance at $\delta 7.15\left(\mathrm{~d}, \mathrm{~J}_{5,6} 1.6 \mathrm{~Hz} 1 \mathrm{H}\right)$ was assigned for $\mathrm{C}_{2}-\mathrm{H} .{ }^{1} \mathrm{H}-{ }^{1} \mathrm{H}$ cosy NMR (Fig (2) e) demonstrated a diagonal relationship between $\beta-\mathrm{H}(\delta 7.15)$, and $\alpha-\mathrm{H}(\delta 7.73)$. ${ }^{13} \mathrm{C}$ NMR spectrum (Fig (2) f ) showed a $\mathrm{C}_{22}$ system. The mass spectrum (Fig (2) g) showed m/z $267.4(60 \%)$ for the molecular Ion. Other fragment at $\mathrm{m} / \mathrm{z} 101$ (100\%) (Base peak) and $\mathrm{m} / \mathrm{z} 267.1$ $(50 \%)$ is due to loss of amino group. The fragment at $\mathrm{m} / \mathrm{z} 239.0$ $(80 \%)$ is due to loss of the amine group and carbon monoxide. 


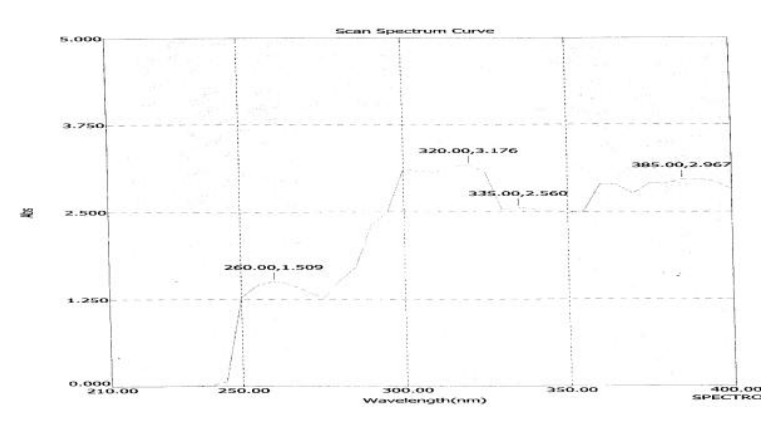

Fig. 2, a :UV spectrum of 3-hydroxy-4'-methoxy-4-(N-methylpiperazinomethyl) chalcone (2).

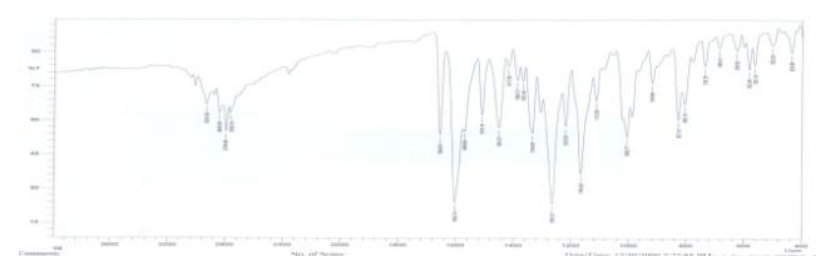

Fig. 2, b :IR spectrum of 3-hydroxy-4'-methoxy-4-(N-methylpiperazinomethyl) chalcone (2).

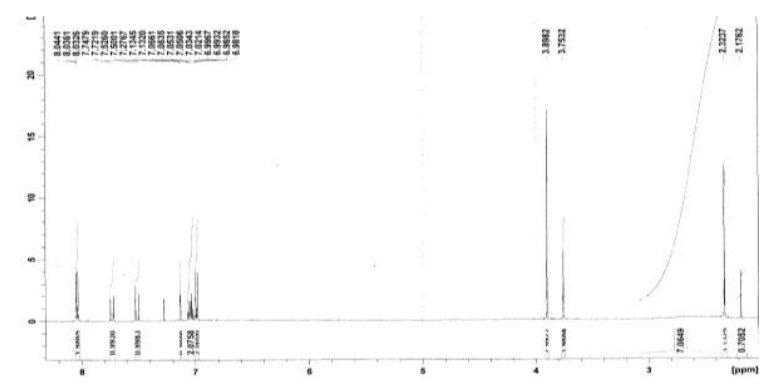

Fig. 2, c : ${ }^{1} \mathrm{H}-\mathrm{NMR}$ spectrum of 3-hydroxy-4'-methoxy-4-(N-methylpiperazinomethyl) chalcone (2).

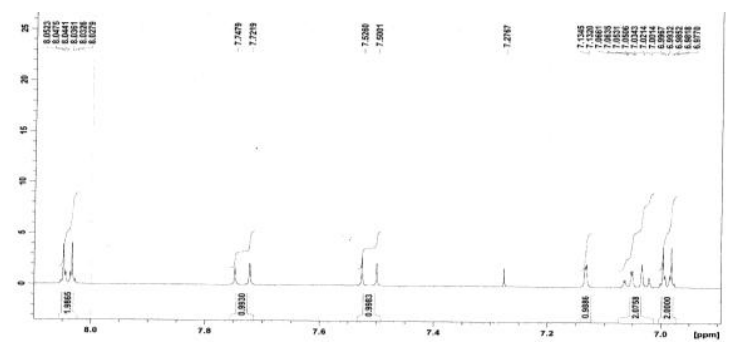

Fig. 2, d : ${ }^{1}$ H-NMR spectrum of 3-hydroxy-4'-methoxy-4-(N-methylpiperazinomethyl) chalcone (2).

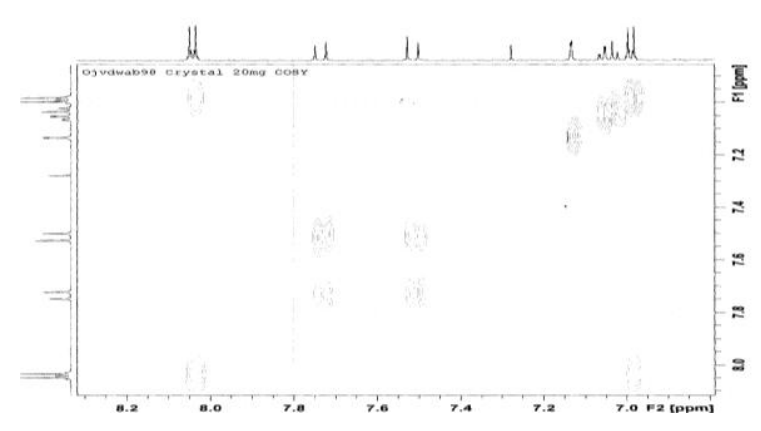

Fig. 2, e : ${ }^{1} \mathrm{H}-{ }^{1} \mathrm{H}$ cosy NMR of 3-hydroxy-4'-methoxy-4-(N-methylpiperazinomethyl) chalcone (2).

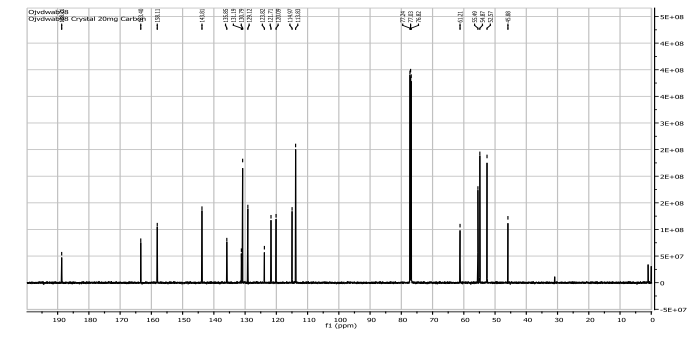

Fig. 2, f : ${ }^{13} \mathrm{C}-\mathrm{NMR}$ spectrum of 3-hydroxy-4'-methoxy-4-(N-methylpiperazinomethyl) chalcone (2).

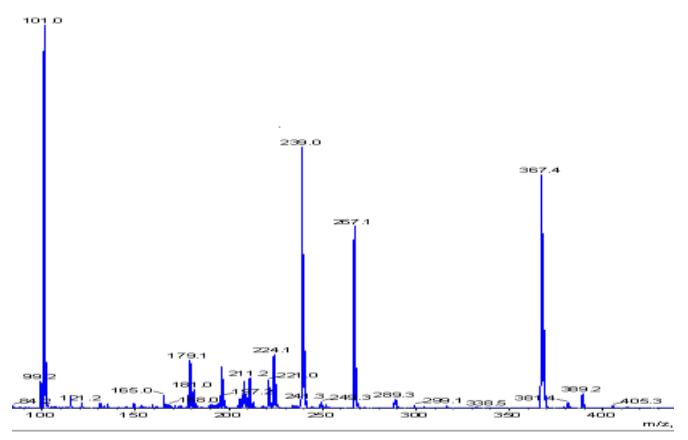

Fig. 2, g : Mass spectrum of 3-hydroxy-4'-methoxy-4-(N-methyl-piperazinomethyl) chalcone (2).

When 3-hydroxy-4'-methoxychalcone, reacting with $\mathrm{N}$-methylpiperazine and formalin in dry acetonitrile under reflux, 3-hydroxy-4'-methoxy-2, 4-bis-(N-methylpiperazinomethyl) chalcone (3) was obtained m.p $122-123{ }^{\circ} \mathrm{C},(58 \%)$.

The UV spectrum (Fig (3) a) showed $\lambda_{\max }$ (ethanol) $260,320,335$ and $385 \mathrm{~nm}$. The IR spectrum $v(\mathrm{KBr})$ (Fig (3) b) showed 827 (C-H, Ar, bending), 1164 (C-N), 1265 (C-O), 1450, 1510, 1602 (C=C, Ar, st,vib), 1654 (C=O. st, vib), 2765, 2794 (C-H, aliphatic), $2840(\mathrm{C}-\mathrm{H}, \mathrm{Ar})$ and $2931(\mathrm{OH}) \mathrm{cm}^{-1}$. The ${ }^{1} \mathrm{H}-\mathrm{NMR}$ spectrum (Fig (3) c) showed two singlet at $\delta 2.26(3 \mathrm{H}), \delta 2.29(3 \mathrm{H})$ assigned for the two methyl groups. The two multiplets at $\delta 2.39-2.49(8 \mathrm{H})$, and $\delta$ 2.49-2.68 $(8 \mathrm{H})$ were assigned for the protons of two $\mathrm{N}$-methylpiperazine rings. The two methylene groups $=\mathrm{N}-\mathrm{CH}_{2}-$ appeared as singlets at $\delta 3.67$, and $\delta$ 3.80. The methoxy group resonates at $\delta 3.89$. The resonance at $\delta 7.35(\mathrm{~d}$, $14.5 \mathrm{~Hz}, 1 \mathrm{H}$ ), was assigned for $\mathrm{C}_{\beta}-\mathrm{H}$, while the doublet at $\delta 8.15$ $(14.5 \mathrm{~Hz}, 1 \mathrm{H})$ was assigned for $\mathrm{C}_{\alpha}-\mathrm{H}$. The doublet at $\delta 7.04(\mathrm{~J} 6$, $57.7 \mathrm{~Hz}, 1 \mathrm{H})$ is characteristic of $\mathrm{C}_{5}-\mathrm{H}$, while the signal at $\delta 7.15(\mathrm{~d}$ $\left.\mathrm{J}_{5,6} 7.7 \mathrm{~Hz} 1 \mathrm{H}\right)$ is characteristic of $\mathrm{C}_{6}-\mathrm{H}$. The doublet at $\delta 7.00(\mathrm{~d}$, $8.8 \mathrm{~Hz}, 2 \mathrm{H}$ ) was assigned for $\mathrm{C}_{3^{\prime}}$ and $\mathrm{C}_{5^{\prime}}-\mathrm{H}$, while the signal at $\delta$ $8.14(\mathrm{~d}, 8.8 \mathrm{~Hz}, 2 \mathrm{H})$ was assigned for $\mathrm{C}_{2} \mathrm{C}_{6}{ }^{-} \mathrm{H} .{ }^{13} \mathrm{C}$ NMR spectrum (Fig (3) e) showed a $\mathrm{C}_{28}$ system. Apt experiments(Fig (3) f) showed 11 carbons in negative mode (one $\mathrm{OCH}_{3}$, two Me and eight $=\mathrm{CH}-$ ), and 17 carbons in positive mode (ten $\mathrm{CH}_{2^{-}}$, and seven quaternary carbons).

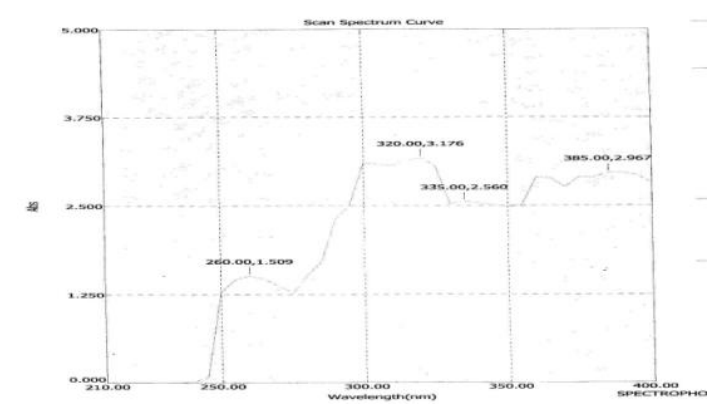

Fig. 3, a : UV spectrum of 3-hydroxy-4'-methoxy-2,4-bis-(N-methylpiperazinomethyl) chalcone (3). 


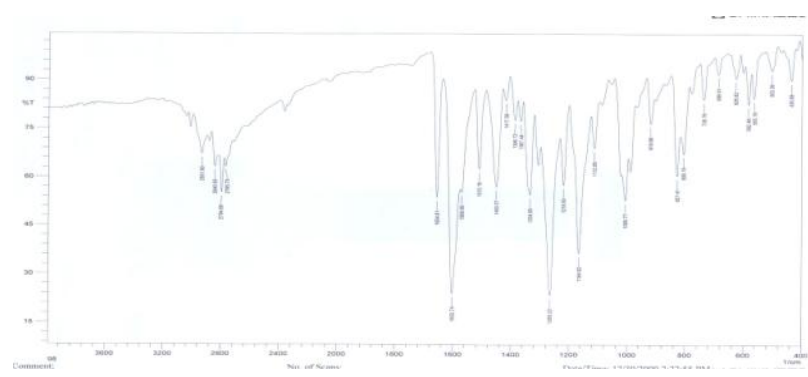

Fig. 3, b : IR spectrum of 3-hydroxy-4'-methoxy-2,4-bis-(N-methylpiperazinomethyl) chalcone (3)

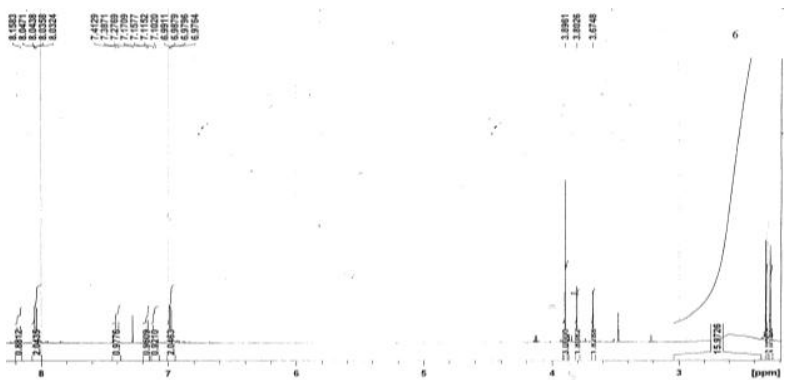

Fig. 3, c: ${ }^{1} \mathrm{H}-\mathrm{NMR}$ spectrum of 3-hydroxy-4'-methoxy-2,4-bis-(N-methylpiperazinomethyl) chalcone (3).

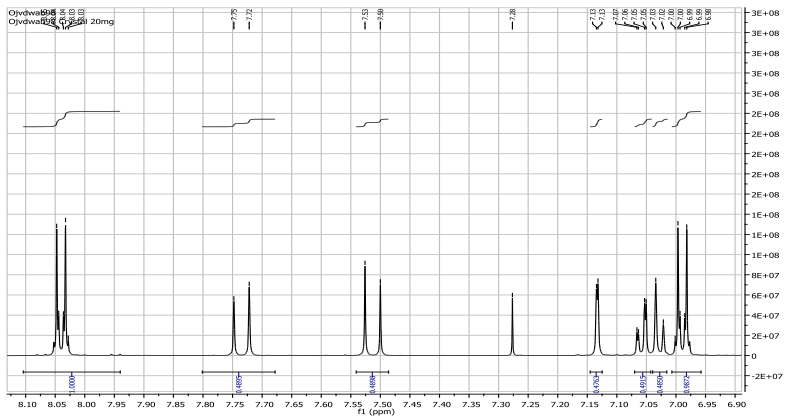

Fig. 3, d: ${ }^{1} \mathrm{H}-\mathrm{NMR}$ spectrum of 3-hydroxy-4'-methoxy-2,4-bis-(N-methylpiperazinomethyl) chalcone (3).

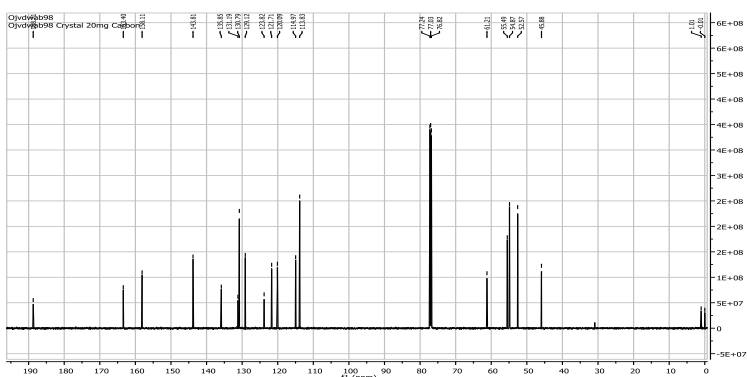

Fig. 3,e: ${ }^{13} \mathrm{C}-\mathrm{NMR}$ spectrum of 3-hydroxy-4'-methoxy-2,4-bis-(N-methylpiperazinomethyl) chalcone (3).

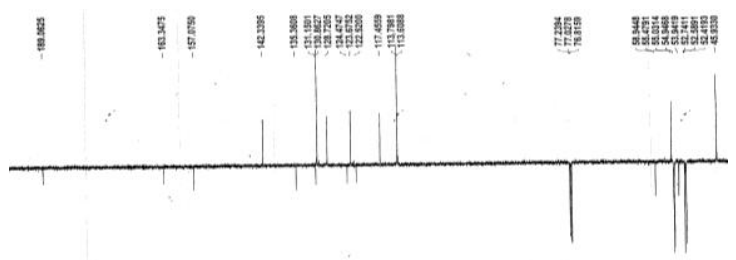

Fig. 3, f : Apt experiments of 3-hydroxy-4'-methoxy-2, 4-bis-(N-methylpiperazinomethyl) chalcone (3).

\section{Conclusion}

The aminomethylation of chalcone by reaction with formaldehyde and suitable amine in acetonitrile was achieved and characterization of the products and their intermediates by spectroscopic methods: UV, IR, and NMR and mass spectrometry were discussed.

\section{Acknowledgements}

My hearty thank are extended to Professor J .H. van der Westhuizen , Chemistry Department, University of Free State (UOFS), South Africa, for accommodation in his laboratories and for his tremendous help.

\section{References}

[1] Abraham G., et Al., Synthesis and anti-inflammatory activity of three nitro chalcones; J. Bioorg and Med. Chem. Lett. 2003; 23:5519.

[2] Afaf, H., Fahmy, H. H. and Ali, A., Synthesis and An-timicrobial Activity of Some New Benzimidazole De-rivatives, Molecules, 2000; 5: 1429. http://dx.doi.org/10.3390/51201429.

[3] Dimmock, J. R. and Kamar, P., Anticancer and cyto-toxic properties of Mannich basses, Curr. Med., Chem. 1997; 4:1.

[4] Ebru, M., Halise, I. G. and Cuvit, K., Synthesis of 1-Aryl-3phenethylamino-1- propanone Hydrochlorides as Possible Potent Cytotoxic Agents, Molecules, 2007; 12: 2579 http://dx.doi.org/10.3390/12122579.

[5] Herencia, F. et al., Synthesis and anti-inflammatory activity of chalcone derivatives, J. Bioorg. Med. Chem. Lett.1998; 8: 1169. http://dx.doi.org/10.1016/S0960-894X (98)00179-6.

[6] Ina-Gull, H. et.al., Cytotoxic activities of mono and bis Mannich bases derived from acetophenone against Renca and Jurkat cell, pharmaceutica Acta Helvetiae, 2000; 74:393.

[7] Janathan, R. et al., 4-(beta-Arylvinyl)-3-(beta-arylvinylketo)-1-ethyl4-piperidinols and related com-pounds: a novel class of cytotoxic and anticancer agents, J. Med. Chem., 1998; 41: 4012. http://dx.doi.org/10.1021/jm9801455.

[8] Jontathan, R. et al., Cytoxic Evaluation of Some 3,5-Diarylidene-4piperidones and Various Related Quater-nary Ammonium Compounds and Analogs, Eur. J. Med. Chem., 2002; 37: 35.

[9] Ko, H. H., Tsao, I. T., Wang, J. P., Lin, C. N., Struc-ture-Activity Relationship Studies on Chalcone Deriv-atives:The Potent Inhibition of Chemical Mediator Release. Bioorg. Med. Chem., 11, 105-111, J. Bioorg. Med., 2003; 11:105. http://dx.doi.org/10.1016/S0968-0896 (02)00312-7.

[10] Li, R. et al., In Vitro antimalarial activity of chalcones and their derivatives, J. Med. Chem., 1995; 38: 5031 http://dx.doi.org/10.1021/jm00026a010.

[11]Lin, Y. M. ET. al., Chalcones and flavonoids as anti-tuberculosis agents, J. Bioorg.Med. Chem., 2002; 10.

[12]Lopez, S. N. et al., in vitro antifungal evaluation and structure-activity relationships of a new series of chalcone derivatives and synthetic analogues, with inhibitory properties against polymers of the fungal cell wall, J. Bioorg. Med. Chem., 2001; 9: 1999. http://dx.doi.org/10.1016/S0968-0896(01)00116-X.

[13] Mutlu, D. A. and Vnsal, C., Synthesis of Some Novel Mannich Bases Derived From Allomaltol and Evaluation of Their Anticonvulsant Activities, Hacettepe University Journal of The Faculty of Pharmacy, 2007; 27(1): 1

[14]Nabil, M. et al., Synthesis of some 6-(alkylamino) methylhexahydro5-aryl and aralkyl-4, 7-methanoindan -5-ols and certain of their propionate eater as analgesics, Journal of Islamic Acedemy of Science, 1993; 6(2): 99

[15]Ozan, R., Zuhal, O., Unsal, C., Butent, G. and Abdullah, A. B. Argnei-Forch., Synthesis of and pharmacological studies on the antidepressant and anticonvulsant activities of some 1,3,5-trisubstituted pyrazolines, j. rug Res., 2005; 55 (8):431.

[16]Parmer, V. S. et al., In vitro antimalarial activity of chalcones and their derivatives, J. Bioorg. Med. Chem., 2003; 11: 913.

[17]Robert, M. et al., Synthesis of Abyssinone II and related compounds as potential chemopreventive agents, Eur. J. Med. Chem.,2006; 41: 263 . http://dx.doi.org/10.1016/j.ejmech.2005.09.008.

[18]Stephen, J., Judith, J. and Leslie, M., Synthesis and Antimalarial Effects of 4-(7- Chloro-4-quinolinyl) ami-no]-2-[(diet hylamino) met hyl]-6-alkylphenols and their N'- Oxides J. Med. Chem., 1987; 30: 906. http://dx.doi.org/10.1021/jm00388a027. 
[19]Tamas, L. et al., Synthesis and antibacterial effect of fused Mannich ketones, Eur. J. Med. Chem., 2002; 37: 803. http://dx.doi.org/10.1016/S0223-5234(02)01404-6. 